\title{
Breast epithelial cell proliferation is markedly increased with short-term high levels of endogenous estrogen secondary to controlled ovarian hyperstimulation
}

\author{
Karine Chung $\cdot$ Linda J. Hovanessian-Larsen • Debra Hawes $\cdot$ DeShawn Taylor • \\ Susan Downey $\cdot$ Darcy V. Spicer $\cdot$ Frank Z. Stanczyk $\cdot$ Sherfaraz Patel $\cdot$ \\ A. Rebecca Anderson • Malcolm C. Pike • Anna H. Wu $\cdot$ Celeste Leigh Pearce
}

Received: 31 October 2011/Accepted: 1 November 2011/Published online: 15 November 2011

(c) The Author(s) 2011. This article is published with open access at Springerlink.com

\begin{abstract}
Oocyte donors have high serum estradiol (E2) levels similar to the serum levels seen in the first trimester of pregnancy. We report in this article our studies comparing cell proliferation, Ki67 (MIB1), and estrogen and progesterone receptor levels (ER $\alpha, \mathrm{PRA}$, and PRB) in the breast terminal duct lobular units of oocyte donors, women in early pregnancy, and in normally cycling women. Breast tissue and blood samples were obtained from 10 oocyte donors, and 30 pregnant women at 5-18 weeks of gestation. Breast tissue samples were also obtained from 26 normally cycling women. In the oocyte donors: peak E2 (mean $\sim 15,300 \mathrm{pmol} / \mathrm{l}$ ) was reached on the day before oocyte (and tissue) donation; peak progesterone (P4; mean $36.3 \mathrm{nmol} / \mathrm{l}$ ) was reached on the day of donation; Ki67 was positively associated with level of E2, and the mean Ki67 was $7.0 \%$ significantly greater than the mean $1.8 \%$ of cycling women. In the pregnant women: mean E2 rose
\end{abstract}

Drs. Chung, Hovanessian-Larsen, Hawes and Taylor are to be joint first authors of this report based on their pivotal contributions to the studies reported here.

K. Chung $\cdot$ D. Taylor $\cdot$ F. Z. Stanczyk $\cdot$ S. Patel Department of Obstetrics and Gynecology, Keck School of Medicine, University of Southern California, Los Angeles, CA 90033, USA

L. J. Hovanessian-Larsen

Department of Radiology, Keck School of Medicine, University of Southern California, Los Angeles, CA 90033, USA

D. Hawes

Department of Pathology, Keck School of Medicine, University of Southern California, Los Angeles, CA 90033, USA

\section{S. Downey}

Department of Surgery, Keck School of Medicine, University of Southern California, Los Angeles, CA 90033, USA from $\sim 2,000 \mathrm{pmol} / 1$ at 5 weeks of gestation to $\sim 27,000 \mathrm{pmol} / \mathrm{l}$ at 18 weeks; mean $\mathrm{P} 4 \mathrm{did}$ not change from $\sim 40 \mathrm{nmol} / 1$ until around gestational week 11 when it increased to $\sim 80 \mathrm{nmol} / \mathrm{l}$; mean $\mathrm{Ki} 67$ was $15.4 \%$ and did not vary with gestational age or E2. Oocyte donors have greatly increased levels of E2 and of breast-cell proliferation, both comparable in the majority of donors to the levels seen in the first trimester of pregnancy. Whether their short durations of greatly increased E2 levels are associated with any long-term beneficial effects on the breast, as occurring in rodent models, is not known.

Keywords Oocyte donors · Breast epithelium · Estradiol · Pregnancy

\section{Introduction}

Estradiol (E2) and progesterone (P4) are critically important in the pathogenesis of breast cancer $[1,2]$. Infertility

\footnotetext{
D. V. Spicer

Department of Medicine, Keck School of Medicine, University of Southern California, Los Angeles, CA 90033, USA

F. Z. Stanczyk - A. R. Anderson - M. C. Pike ·

A. H. Wu - C. L. Pearce

Department of Preventive Medicine, Keck School of Medicine,

University of Southern California, Los Angeles, CA 90033, USA

M. C. Pike ( $\square)$

Department of Epidemiology and Biostatistics, Memorial SloanKettering Cancer Center, 307 E. 63rd Street, New York, NY 10065, USA

e-mail: pikem@mskcc.org
} 
treatments involving controlled ovarian hyperstimulation are known to cause a transient large increase in serum E2 comparable to the levels seen in the first trimester of pregnancy, whereas $\mathrm{P} 4$ levels are no greater than those that are seen in the luteal phase of the menstrual cycle [3, 4]. The effects of this short-term high endogenous E2 exposure on normal breast tissue are unknown.

As part of studies of the changes in human breast associated with pregnancy, we have studied breast tissue from naturally cycling nulliparous and parous women and from women immediately after a pregnancy termination [5]. We report here our studies of the epithelium of the breast terminal duct lobular unit (TDLU) at the end of the ovarian stimulation phase in 10 oocyte donors (women having ovarian hyperstimulation to donate oocytes for use by other women). We report on proliferation (Ki67), estrogen receptor $\alpha(\mathrm{ER} \alpha)$, and progesterone receptors $\mathrm{A}$ and $\mathrm{B}$ (PRA and PRB) in these oocyte donors, and compare these results to those obtained from 30 women sampled between 5 and 22 weeks of gestation (weeks since last menstrual period, LMP) [5] and to the results obtained from 26 cycling women.

\section{Materials and methods}

All study protocols described here were approved by the Institutional Review Boards (IRBs) of the USC Keck School of Medicine and where appropriate of the Department of Defense Congressionally Directed Breast Cancer Research Program. The prospectively collected samples were obtained after the women had signed an informed consent. The samples obtained retrospectively from the cycling women were used after the women had been contacted and given consent for their samples to be used.

\section{Oocyte donors}

Women attending the In vitro Fertilization Clinic at the University of Southern California (USC) to donate oocytes for the use of other women were invited to volunteer for this study. Women who expressed a desire to participate underwent a routine clinical breast examination; no abnormalities were found. The research-related procedures included a menstrual and reproductive history questionnaire, a blood sample on the day of oocyte retrieval and a breast biopsy immediately after the oocyte retrieval or on the day before if necessary.

Subjects underwent standard clinical protocols for ovarian stimulation. Daily subcutaneous injections of follicle stimulating hormone for approximately 10-14 days with regular monitoring of serum E2 and ultrasound measurement of ovarian follicles. When the follicles were determined to be mature, human chorionic gonadotropin (10,000 IU) was administered by subcutaneous injection and oocytes were retrieved under intravenous sedation by trans-vaginal ultrasound guided needle aspiration approximately $36 \mathrm{~h}$ later.

Ultrasound guided 14-gauge core-needle breast biopsy tissue was collected from a region of ultrasonographically normal dense breast tissue in the upper outer quadrant of the breast. Samples of these tissues were formalin fixed paraffin embedded (FFPE) in a routine manner at the USC Department of Pathology.

\section{Pregnant women}

The recruitment of pregnant women has been described previously [5]. Briefly, the pregnant samples were collected from women who had undergone a pregnancy termination within the preceding $10 \mathrm{~min}$; and the blood and tissue samples were collected and processed in like manner to that described above for oocyte donors.

\section{Normally cycling women}

The recruitment of normally cycling women has also been described previously [5]. Briefly, the samples from cycling women were obtained from women undergoing a reduction mammoplasty; some of these samples were collected prospectively and others from FFPE tissue blocks, that had been routinely processed at the USC Department of Pathology. These were much larger tissue samples than are obtained at core-needle biopsy but were processed in like manner. No blood samples were obtained at the time of surgery from the retrospectively identified women and hormone values are not reported on here for the cycling women.

Immunohistochemistry

Immunohistochemical (IHC) analysis of the FFPE samples was performed as follows: Multiple adjacent FFPE sections were cut at $5 \mu \mathrm{m}$, deparaffinized and hydrated. All slides were subject to antigen retrieval which was performed by heating the slides in $10 \mathrm{mmol} / \mathrm{l}$ sodium citrate buffer $(\mathrm{pH}$ 6) at $110^{\circ} \mathrm{C}$ for $30 \mathrm{~min}$ in a pressure cooker in a microwave oven. Endogenous peroxidase activity was blocked by incubation in $3 \% \mathrm{H}_{2} \mathrm{O}_{2}$ for $20 \mathrm{~min}$, followed by blocking of nonspecific sites with SuperBlock blocking buffer (Pierce, Rockford, IL, USA) for $1 \mathrm{~h}$ both at room temperature (see [5]).

The sections were incubated with the following antibodies: MIB1, a proliferation marker, the mouse monoclonal antihuman Ki67 antibody (Dako Cytomation, Carpenteria, CA, USA) at a concentration of 1:500; PRA, 
the mouse monoclonal antibody NCL-PGR-312 (Novocastra Laboratories Ltd, Newcastle upon Tyne, UK) at a concentration of 1:5,000; $\mathrm{PRB}$, the mouse monoclonal antibody NCL-PGR-B (Novocastra Laboratories Ltd, Newcastle upon Tyne, UK) at a concentration of 1:100; and $\mathrm{ER} \alpha$, the mouse monoclonal antibody ER Ab-12 (Clone 6F11) (Neomarkers, Kalamazoo, MI, USA) at a concentration of 1:100. After incubation with the primary antibodies, antibody binding was localized with the secondary antibody for $45 \mathrm{~min}$ and then with the $\mathrm{ABC}$ staining kit from Vector Laboratories (Burlingame, CA, USA) according to the manufacturer's instructions, and peroxidase activity was detected using 3,3'-diaminobenzidine substrate solution (DAB; Biocare, Concord, CA, USA). A wash step with phosphate buffer solution (PBS) for $10 \mathrm{~min}$ was carried out between each step of the immunostaining. Slides were counterstained with hematoxylin and mounted in mounting medium for examination.

We generally assessed all TDLUs on a single slide. A clear distinction between luminal-epithelial cells and myoepithelial cells in TDLUs is frequently difficult to make on conventionally stained slides. For this reason we counted the total numbers of luminal-epithelial + myoepithelial cells (epithelial cells) and the percentage of them positive for the relevant marker using the Automated Cellular Imaging System II (ACIS II, Clarient, Aliso Viejo, CA, USA), which digitizes the images and permits the user to identify and quantitate relevant areas on a high-resolution computer screen based on color differentiation. The ACIS II software program does not function optimally when both nuclear and cytoplasmic staining is present. Due to some background cytoplasmic staining in addition to nuclear positivity found in the ER $\alpha$ slides from the pregnant subjects, we used conventional light microscopy and manual counting for assessing the TDLUs in these cases; we counted 500 epithelial cells except in a few cases with scant epithelial tissue. Only nuclear staining was regarded as positive staining.

\section{Blood specimens}

The blood specimens obtained during oocyte stimulation and at breast biopsy were processed in a standard manner and the serum frozen at $-20^{\circ} \mathrm{C}$. E2 and $\mathrm{P} 4$ were quantified by specific radioimmunoassay as described previously $[6$, 7]. SHBG was measured by a chemiluminescent immunoassay on the Immulite Analyzer (Siemens Medical Solutions Diagnostics, Malvern, PA, USA). The coefficients of variation for E2, P4 and SHBG were 14.7, 7.8, and $3.7 \%$, respectively. No serum results were given in our previous publication on pregnant and naturally cycling women [5]. Non-SHBG-bound E2 was calculated by the method of Södergård et al. [8] using the parameters given by Dunn et al. [9].

Statistical analysis

We analyzed these data using the standard statistical package program, Stata 11 (Stata Corporation, College Station, TX, USA). Differences in expression and tests for trend in expression were tested for significance by standard $t$ tests and regression tests after transformation of the variables to achieve more normal distributions of values (square root transformations of ER $\alpha$, PRA, and PRB; and logarithmic transformation of MIB1) [5]. E2, P4, and SHBG values were logarithmically transformed. Testing for the effects of prior births, age and ethnicity on the results were carried out by inclusion of terms for these in regression analyses. All statistical significance levels $(P$ values) quoted are two sided.

\section{Results}

We recruited 13 oocyte donors who provided informed consent. One decided to withdraw from the study prior to undergoing the breast biopsy. The remaining 12 completed the study protocol. The biopsies from two of the women had no epithelium in the specimen - these women were excluded from further study. Of the remaining 10, eight had their biopsy on the day of oocyte donation and two on the day before due to their unavailability on the donation day.

Figure 1 shows the E2 and P4 values of the individual subjects in the 7 days before oocyte retrieval. E2 increased steadily in each subject until the day before oocyte retrieval —on the day of retrieval, E2 had fallen from a mean of $\sim 15,300$ to $\sim 6,000 \mathrm{pmol} / \mathrm{l}$. P4 also increased steadily in each subject; the mean value increased from $1.1 \mathrm{nmol} / \mathrm{l}$ at 7 days before oocyte retrieval to $4.1 \mathrm{nmol} / \mathrm{l}$ at 2 days before retrieval, and then, after hCG treatment, to $18.0 \mathrm{nmol} / \mathrm{l}$ on the day before oocyte retrieval, and to $36.3 \mathrm{nmol} / \mathrm{l}$ on the day of retrieval. For comparison, in naturally cycling women, the follicular phase maximum E2 is $\sim 1,100 \mathrm{pmol} /$ 1, the luteal phase maximum E2 is $\sim 510 \mathrm{pmol} / \mathrm{l}$, and the luteal phase maximum $\mathrm{P} 4$ is $\sim 40 \mathrm{nmol} / \mathrm{l}$ [10].

Figure 2 shows the relationships of serum E2 and P4 to gestational age in the pregnant women [5]. E2 increased steadily with gestational age, from $\sim 2,000 \mathrm{pmol} / \mathrm{l}$ at 5 weeks to $\sim 27,000 \mathrm{pmol} / \mathrm{l}$ at 18 weeks of gestation. $\mathrm{P} 4$ did not change from the mid-luteal peak of $\sim 40 \mathrm{nmol} / \mathrm{l}$ until around week 11 of gestation, after which it increased to $\sim 80 \mathrm{nmol} / \mathrm{l}$.

Figure 3 shows the relation between Ki67 (MIB1) for the oocyte donors plotted against their E2 on the day before 

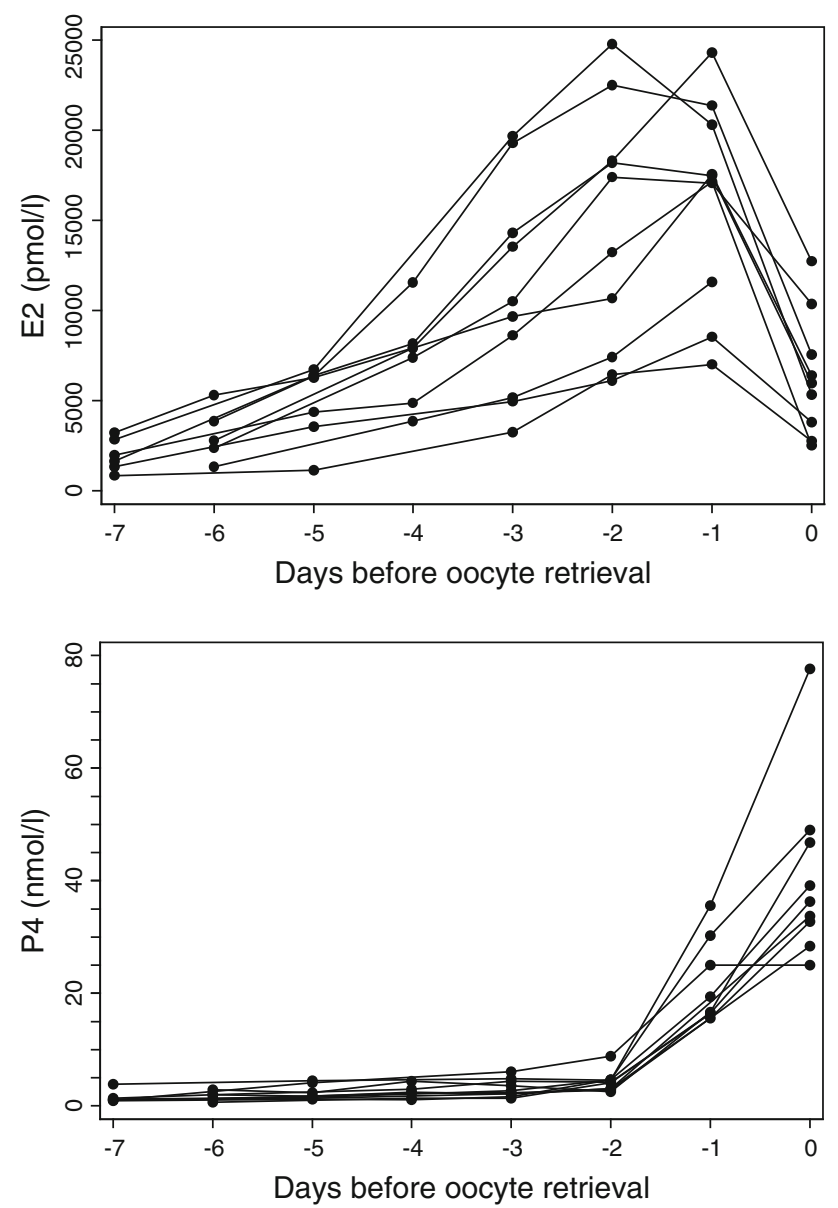

Fig. 1 Individual oocyte donor estradiol (E2) and progesterone (P4) values in the week before oocyte retrieval

biopsy, and for the 30 pregnant women plotted against their E2 on the day of biopsy, while Fig. 4 shows the relation between Ki67 for the 10 oocyte donors and the 30 pregnant women plotted against their P4 on the day of biopsy.

For the oocyte donors, there was a strong positive relationship between Ki67 and E2 on the day before biopsy (see Fig. 3)-correlation, $r=0.76(P=0.010)$; while the correlation between Ki67 and E2 on the day of biopsy was much weaker- $r=0.17(P=0.65)$ (data not shown). For the oocyte donors, there was no significant relationship between Ki67 and P4 on the day of biopsy or P4 on the day before biopsy. For the pregnant women, there was no relationship between Ki67 and E2 or P4.

The means (and 95\% confidence intervals) of the proportion of epithelial cells with positive nuclear staining for Ki67, ER $\alpha, \mathrm{PRA}$, and PRB are given in Table 1.

The Ki67 mean value was increased from $1.8 \%$ in the cycling women to $7.0 \%$ in the oocyte donors $(P=0.003)$. The Ki67 mean value in the seven oocyte donors whose serum E2 values on the day before biopsy exceeded $10,000 \mathrm{pmol} / \mathrm{l}$ was $14.1 \%$, very close to the mean value of $15.4 \%$ seen in the pregnant women.
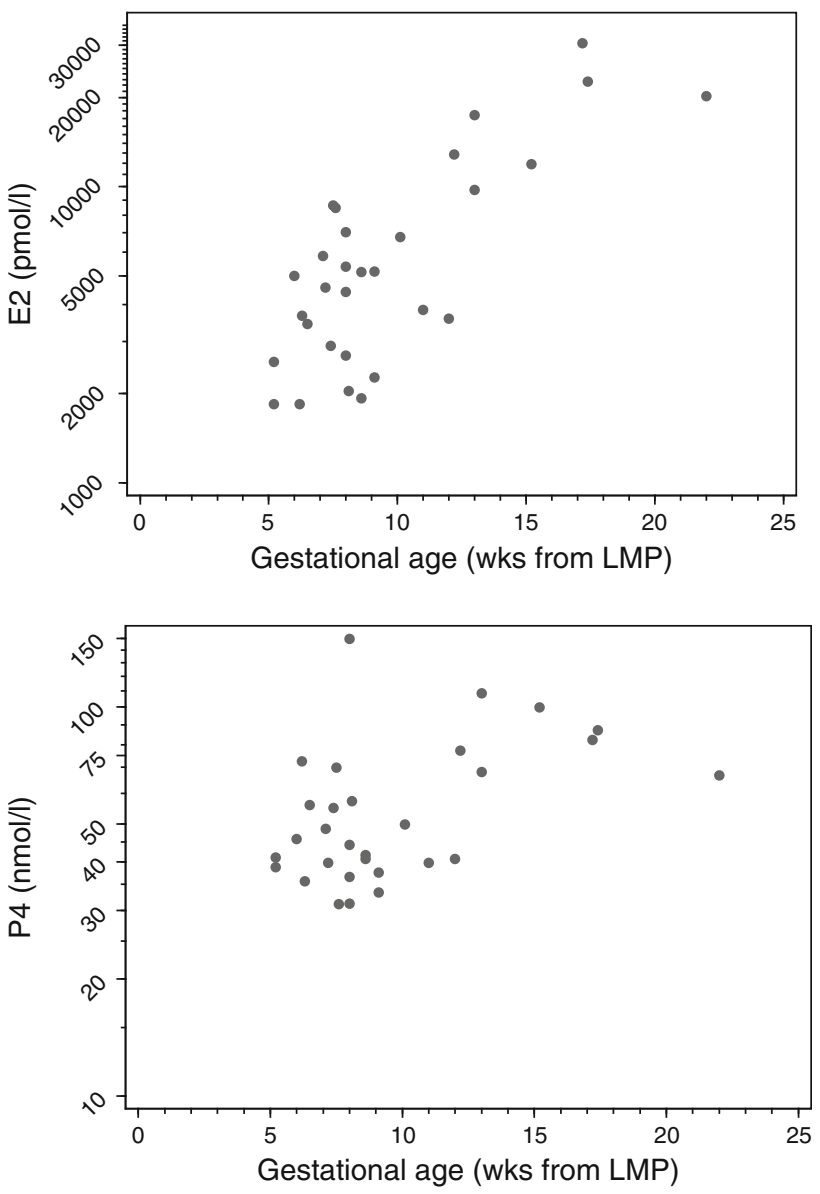

Fig. 2 Individual pregnant woman estradiol (E2) and progesterone (P4) values versus gestational age

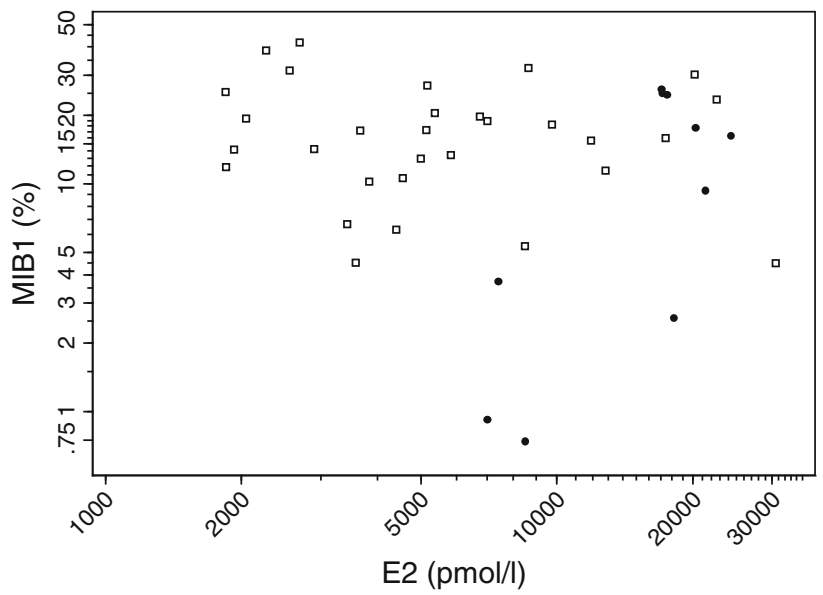

Fig. 3 Individual woman TDLU epithelial cell MIB1 values versus estradiol (E2) values-E2 values for oocyte donors on the day before biopsy (filled circle); E2 values for "pregnant" women on the day of biopsy (open square)

The ER $\alpha$ mean value was lower in oocyte donors $(6.8 \%)$ than in cycling women (12.0\%). The PRA mean value was slightly lower in the oocyte donors $(17.8 \%)$ than in the cycling women $(23.5 \%)$, but was not as low as in the 


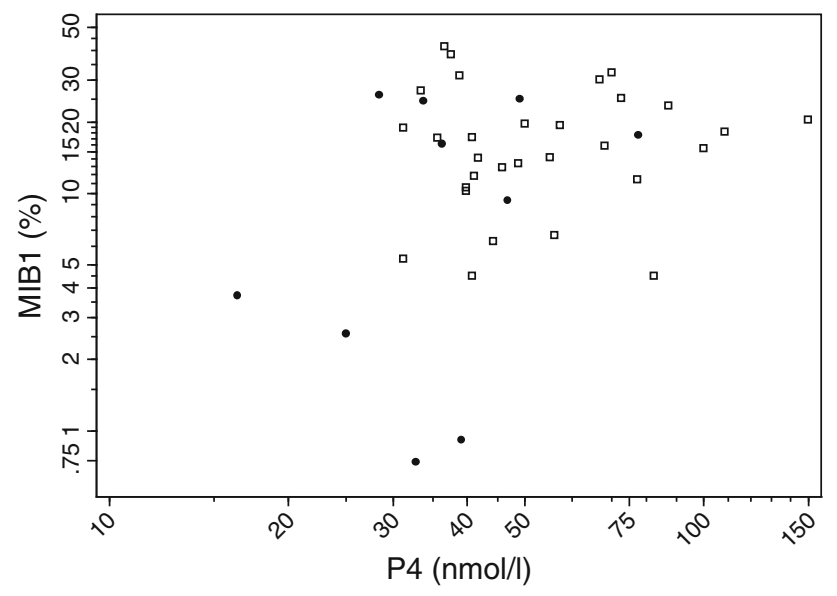

Fig. 4 Individual woman TDLU epithelial cell MIB1 values versus progesterone ( $\mathrm{P} 4)$ values on day of biopsy-oocyte donors (filled circle); "pregnant" women (open square)

Table 1 Mean (with 95\% confidence limits) percentages of Ki67, PRA, PRB, and ER $\alpha$ in oocyte donors, pregnant women, and naturally cycling women

\begin{tabular}{llrrrc}
\hline & Group & Mean $^{\mathrm{a}}$ & $\mathrm{lcl}^{\mathrm{a}}$ & $\mathrm{ucl}^{\mathrm{a}}$ & $P$ value \\
\hline Ki67 & Oocyte donor $(N=10)$ & 7.0 & 3.0 & 16.5 & \\
& Pregnant $(N=30)$ & 15.4 & 12.4 & 19.1 & 0.016 \\
& Cycling $(N=26)$ & 1.8 & 1.2 & 2.7 & 0.003 \\
ER $\alpha$ Oocyte donor & 6.8 & 4.3 & 9.9 & \\
& Pregnant & 11.0 & 7.9 & 14.6 & 0.15 \\
& Cycling & 12.0 & 9.2 & 15.2 & 0.034 \\
PRA & Oocyte donor & 17.8 & 13.4 & 22.9 & \\
& Pregnant & 3.9 & 2.5 & 5.5 & $<0.001$ \\
& Cycling & 23.5 & 16.2 & 32.2 & 0.37 \\
PRB & Oocyte donor & 16.9 & 11.3 & 23.6 & \\
& Pregnant & 12.8 & 9.4 & 16.8 & 0.31 \\
& Cycling & 19.2 & 13.3 & 26.0 & 0.67 \\
\hline
\end{tabular}

${ }^{a}$ Calculations were made with transformed values-logarithmic for MIB1, and square root for ER $\alpha, P R A$, and PRB values. lcl and ucl are lower and upper $95 \%$ confidence interval values, respectively

b $P$ values are for comparisons with oocyte donors

pregnant women (3.9\%). The difference between the oocyte donors and the cycling women was not statistically significant. The PRB mean values were similar in all three groups of women.

The results shown in Table 1 are the values as measured without adjustment for the potential confounders of parity, age, or ethnicity. Adjustment for ethnicity and age had little effect on any of the values shown. We previously reported that parous naturally cycling women had significantly lower PRA values than nulliparous naturally cycling women [5], and lower values of Ki67, ER $\alpha$, and PRB, but the differences for these factors were not statistically significant. Parity had no effect on Ki67, ER $\alpha$, and PRA in pregnant women, but the PRB mean was marginally statistically significantly greater in the parous group $(P=0.049)$. Eight of the 10 oocyte donors were nulliparous, so that we had no power to investigate the effects of parity in the oocyte donors. Adjustment for parity made little difference to the comparisons shown in Table 1 and no differences to the statistical significance of the comparisons.

\section{Discussion}

This is the first study, to our knowledge, to evaluate the immediate effects of short-term exposure to high levels of endogenous estrogen on the breast epithelium of women. In oocyte donors, the level of breast-cell proliferation was positively associated with their serum E2, and a large increase in breast-cell proliferation, similar to the increase seen in pregnant women, occurred in six of the seven oocyte donors whose serum E2 exceeded 10,000 pmol/l. In contrast, the pregnant women demonstrated the same level of breast-cell proliferation over the whole range of observed serum E2 values from $\sim 1,800 \mathrm{pmol} / \mathrm{l}$ to $\sim 30,000 \mathrm{pmol} / \mathrm{l}$ with no evidence of a dose-response.

When we re-plotted Fig. 3 using non-SHBG-bound E2 rather than E2, a very similar picture was seen. It is unlikely that the contribution of estriol (E3) and estetrol (E4) to the overall estrogenic milieu in pregnant women explains their higher proliferation because these two hormones are at very low levels through gestational week 8 where most of our subjects with E2 concentrations below $10,000 \mathrm{pmol} /$ 1 lie (Fig. 3 [11-13]). Higher levels of proliferation in pregnant women may be due to their longer exposure to high levels of E2 and to longer exposure to luteal (or higher) levels of P4, it may also be due to their higher ER $\alpha$ expression (see below).

Prolactin is a breast-cell mitogen and prolactin levels increase starting around week 5 of gestation [14]. The proliferation effect of E2 may be enhanced as prolactin has been reported to induce estrogen receptor expression in the breast $[15,16]$. Prolactin levels vary greatly during the day with a maximum during sleep and a rapid fall-off on waking. Time of blood draw was not recorded for our study subjects and therefore does not provide useful information on the comparison of prolactin levels in oocyte donors and pregnant women.

We previously reported that PRA decreased steadily with gestational age in pregnant women [5] and although there was already some decrease early on in pregnancy, PRA only reached very low levels $(\sim 1 \%)$ after week 12 of gestation. There was a non-statistically significant $24 \%$ reduction of PRA in oocyte donors compared with naturally cycling women, but this was small relative to the 
reduction seen in pregnant women. We also previously reported that "overall there was little difference in ER $\alpha$ expression between non-pregnant and pregnant subjects," but the data strongly suggested that "ER $\alpha$ expression is increased early on in pregnancy ( $<8$ weeks of gestation) and then declines to lower levels than are seen in nonpregnant subjects." In contrast, ER $\alpha$ expression in oocyte donors was low.

Based on a strictly limited amount of epidemiological data but considerable data from rodent experiments (see below), it is possible that a short-term pregnancy and short-term relatively high levels of estrogen may provide some long-term protection against breast cancer. However, the fetoplacental unit in pregnant women is responsible for major endocrinologic changes which are not present in women undergoing ovarian stimulation. Thus, a number of factors in a pregnant woman may contribute to long-term protection against breast cancer. The effects of the high levels of endogenous E2 and P4 achieved during human full-term pregnancy are twofold: a transient increase in breast cancer risk and this is followed by a significant long-term permanent decrease in risk if the pregnancy occurs before around age 32, with the protective effect being greater the earlier the age at which the pregnancy occurs [16-21]. The mechanism for the protective effect remains unclear, but has been attributed in part to hormonal changes, in particular, a reduction in prolactin levels [1], and may possibly be due to hormone-induced changes in breast function leading to lower breast-cell proliferation and possibly other effects. Breast-tissue mRNA expression differences between parous and nulliparous rodents have been observed [22, 23], but whether such changes occur in humans has not been satisfactorily established. There is some evidence that terminated pregnancies may also provide some degree of protection against breast cancer [24]. There are no data available on the effects of a terminated pregnancy on long-term prolactin levels, breast-cell proliferation, or any other possibly relevant factors.

Full-term pregnancy-induced protection against mammary carcinogenesis is consistently observed in rats [2527]. There is again some evidence that terminated pregnancies may also provide protection [26], but this has not been found consistently [27]. The protective effect in the rat can also be achieved by administration of exogenous E2 and P4 [25, 28-30], and two studies have found that with $\mathrm{E} 2+\mathrm{P} 4$ substantial protection could be achieved with as little as 7-10 days of administration [29, 30].

There are large differences in the effects of pregnancy in women and in the rat: the ovary is the sole source of serum estrogen and the major source of serum progesterone in pregnancy in the rat, while in women, the main source of estrogen and progesterone moves from the ovary to the placenta during the latter part of the first trimester [31, 32]. The serum E2 levels in pregnant rats only exceed the values seen in cycling rats during the third week of pregnancy, when it approximately doubles [33-37]. In contrast, the levels of serum E2 are greatly increased in pregnant women - they are increased some fivefold in the first trimester, some 20-fold in the second trimester, and some 40-fold in the third trimester [31]. Whether the results in the rat of short-term E2 exposure at only twice the maximum estrus serum E2 level are of any relevance to the human situation is, thus, not at all clear.

The serum P4 levels in cycling rats vary from 45 to $160 \mathrm{nmol} / \mathrm{l}$ [34-36]; the levels steadily increase during pregnancy and reach a maximum of $320 \mathrm{nmol} / 1$ in the second week, approximately double the maximum seen in the estrus cycle, and then decline in the third week $[38,39]$. The levels of serum P4 in cycling women are lower, at $1.5-40 \mathrm{nmol} / \mathrm{l}$, than the levels in the cycling rat [10]. Serum $\mathrm{P} 4$ levels in women increase steadily during pregnancy-they are increased some twofold in the first trimester, some fourfold in the second trimester, and some 10 -fold in the third trimester compared to the maximum of around $40 \mathrm{nmol} / \mathrm{l}$ at the luteal-phase serum $\mathrm{P} 4$ peak [31]. The maximum seen during pregnancy in women is thus not greatly increased over the maximum level seen in the rat estrus cycle, and the results in the rat of short-term $\mathrm{P} 4$ exposure at the maximum estrus cycle serum $\mathrm{P} 4$ level could possibly be of more relevance to the human situation.

If short-term high levels of serum E2 do provide longterm protection against breast cancer, then we might expect that the breast would change in oocyte donors in a way similar to that seen in pregnant women. The short-term high levels of endogenous E2 did cause a dramatic increase in breast-cell proliferation similar to that associated with pregnancy, but the reduction in PRA was much less than that seen in pregnant women. Studies comparing nulliparous oocyte donors at some time after donation to parous women should be informative.

Acknowledgments The authors wish to express their sincerest gratitude to the women who agreed to be part of the studies discussed in this article. The authors also wish to express their thanks to Ms. Peggy Wan for her extensive help with data handling and statistical analysis. This study was supported by the Department of Defense Congressionally Directed Breast Cancer Research Program Grant BC 044808 to MCP, by the USC/Norris Comprehensive Cancer Center Core Grant P30 CA14089, by funds from the endowment established by Flora L. Thornton for the Chair of the Department of Preventive Medicine at the Keck School of Medicine of USC, and funds from an anonymous donor grant to DT.

Disclosures The authors declare that they do not have financial relationships with any of the organizations that sponsored the research, and they do not have any other real or apparent conflict(s) of interest that may have a direct bearing on the subject matter of the article. 
Open Access This article is distributed under the terms of the Creative Commons Attribution Noncommercial License which permits any noncommercial use, distribution, and reproduction in any medium, provided the original author(s) and source are credited.

\section{References}

1. Bernstein L, Ross RK (1993) Endogenous hormones and breast cancer risk. Epidemiol Rev 15:48-65

2. Pike MC, Wu AH, Spicer DV, Lee S, Pearce CL (2007) Estrogens, progestins, and risk of breast cancer. Ernst Scher Found Symp Proc 1:127-150

3. Papageorgiou T, Guibert J, Goffinet F, Patrat C, Fulla Y, Janssens Y, Zorn JR (2002) Percentile curves of serum estradiol levels during controlled ovarian stimulation in 905 cycles stimulated with recombinant FSH show that high estradiol is not detrimental to IVF outcome. Hum Reprod 17:2846-2850. doi:10.1093/ humrep/17.11.2846

4. Peña JE, Chang PL, Chan LK, Zeitoun K, Thornton MH 2nd, Sauer MV (2002) Supraphysiological estradiol levels do not affect oocyte and embryo quality in oocyte donation cycles. Hum Reprod 17:83-87. doi:10.1093/humrep/17.1.83

5. Taylor D, Pearce CL, Hovanessian-Larsen L, Downey S, Spicer DV, Bartow S, Pike MC, Wu AH, Hawes D (2009) Progesterone and estrogen receptors in pregnant and pre-menopausal nonpregnant normal human breast. Breast Cancer Res Treat 118:161-168. doi:10.1007/s10549-009-0322-4

6. Probst-Hensch NM, Ingles SA, Diep AT, Haile RW, Stanczyk FZ, Kolonel LN, Henderson BE (1999) Aromatase and breast cancer susceptibility. Endocr Relat Cancer 6:165-173. doi:10.1677/erc. 0.0060165

7. Scott JZ, Stanczyk FZ, Goebelsmann U, Mishell DR (1978) A double-antibody radioimmunoassay for serum progesterone using progesterone-3-(0-carboxymethyl) oximino-[125I]-iodo-histamine as radioligand. Steroids 31:393-405

8. Södergård R, Bäckström T, Shanbhag V, Carstensen H (1982) Calculation of free and bound fractions of testosterone and estradiol-17 beta to human plasma proteins at body temperature. J Steroid Biochem 16:801-810. doi:10.1016/0022-4731(82)90038-3

9. Dunn JF, Nisula BC, Rodbard D (1981) Transport of steroid hormones: binding of 21 endogenous steroids to both testosterone-binding globulin and corticosteroid-binding globulin in human plasma. J Clin Endocrin Metab 53:58-68. doi:10.1210/ jcem-53-1-58

10. Goebelsmann U, Mishell DR (1979) The menstrual cycle. In: Mishell DR, Davajan V (eds) Reproductive endocrinology, infertility and contraception. FA Davis, Philadelphia, pp 67-89

11. Lobo RA (1997) Endocrinology of pregnancy. In: Lobo RA, Mishell DR, Paulson RJ, Shoupe D (eds) Mishell's textbook of infertility, contraception, and reproductive endocrinology, 4th edn. Blackwell Science, Malden, pp 183-206

12. Levitz M, Young BK (1977) Estrogens in pregnancy. Vitam Horm 35:109-147

13. Goebelsmann U (1979) Protein and steroid hormones in pregnancy. J Reprod Med 23:166-177

14. Barberia JM, Abu-Fadl S, Kletzky OA, Nakamura RM, Mishell DR (1975) Serum prolactin patterns in early gestation. Am J Obstet Gynecol 121:1107-1110

15. Das R, Vonderhaar BK (1997) Prolactin as a mitogen in mammary cells. J Mammary Gland Biol Neoplasia 2:29-39

16. Gutzman JH, Miller KK, Schuler LA (2004) Endogenous human prolactin and not exogenous human prolactin induces estrogen receptor alpha and prolactin receptor expression and increases estrogen responsiveness in breast cancer cells. J Steroid Biochem Mol Biol 88:69-77. doi:10.1016/j.jsbmb.2003.10.008

17. Trichopoulos D, Hsieh CC, MacMahon B, Lin TM, Lowe CR, Mirra AP, Ravnihar B, Salber EJ, Valaoras VG, Yuasa S (1983) Age at any birth and breast cancer risk. Int J Cancer 31:701-704. doi:10.1002/ijc.2910310604

18. Pike MC, Krailo MD, Henderson BE, Casagrande JT, Hoel DG (1983) 'Hormonal' risk factors, 'breast tissue age' and the ageincidence of breast cancer. Nature 303:767-770. doi:10.1038/ $303767 \mathrm{a} 0$

19. Wohlfahrt J, Melbye M (2001) Age at any birth is associated with breast cancer risk. Epidemiology 12:68-73

20. Albrektsen G, Heuch I, Hansen S, Kvale G (2005) Breast cancer risk by age at birth, time since birth and time intervals between births: exploring interaction effects. Br J Cancer 92:167-175. doi:10.1038/sj.bjc.6602302

21. Schedin P (2006) Pregnancy-associated breast cancer and metastasis. Nat Rev Cancer 9:281-291. doi:10.1038/nrc1839

22. Ginger MR, Gonzalez-Rimbua MF, Gay JP, Rosen JM (2001) Persistent changes in gene expression induced by estrogen and progesterone in the rat mammary gland. Mol Endocrinol 15:1993-2009. doi:10.1210/me.15.11.1993

23. Blakely CM, Stoddard AJ, Belka GK, Dugan KD, Notarfrancesco KL, Moody SE, D'Cruz CM, Chodosh LA (2006) Hormoneinduced protection against mammary tumorigenesis is conserved in multiple rat strains and identifies a core gene expression signature induced by pregnancy. Cancer Res 66:6421-6431; erratum in 2007; 67:844-846. doi:10.1158/0008-5472.CAN-05-4235

24. Collaborative Group on Hormonal Factors in Breast Cancer (2004) Breast cancer and abortion: collaborative reanalysis of data from 53 epidemiological studies, including 83,000 with breast cancer from 16 countries. Lancet 363:1007-1016. doi:10.1016/S0140-6736(04)15835-2

25. Medina D (2004) Breast cancer: the protective effect of pregnancy. Clin Cancer Res 10:380S-384S

26. Sinha DK, Pazik JE, Dao TL (1988) Prevention of mammary carcinogenesis in rats by pregnancy: effect of full-term and interrupted pregnancy. Br J Cancer 57:390-394

27. Russo J, Russo IH (1980) Susceptibility of the mammary gland to carcinogenesis: II. Pregnancy interruption as a risk factor in tumor incidence. Am J Pathol 100:497-512

28. Grubbs CJ, Farnell DR, Hill DL, McDonough KC (1985) Chemoprevention of $N$-nitroso- $N$-methylurea-induced mammary cancers by pretreatment with $17 \beta$-estradiol and progesterone. J Natl Cancer Inst 74:927-931

29. Guzman RC, Yang J, Rajkumar L, Thordarson G, Chen X, Nandi S (1999) Hormonal prevention of breast cancer: mimicking the protective effect of pregnancy. Proc Natl Acad Sci USA 96:2520-2525. doi:10.1073/pnas.96.5.2520

30. Medina D, Peterson LE, Moraes R, Gay J (2001) Short-term exposure to estrogen and progesterone induces partial protection against $N$-nitroso- $N$-methylurea-induced mammary tumorigenesis in Wistar-Furth rats. Cancer Lett 169:1-6. doi:10.1016/S03043835(01)00507-9

31. O'Leary P, Boyne P, Flett P, Beilby J, James I (1991) Longitudinal assessment of changes in reproductive hormones during normal pregnancy. Clin Chem 37:667-672

32. Numan M (1994) Maternal behavior. In: Knobil E, Neill JD (eds) The physiology of reproduction. Raven Press, New York, pp 221-302

33. Kalra PS, Kalra SP (1977) Temporal changes in the hypothalamic and serum luteinizing hormone-releasing hormone (LH-RH) levels and the circulating ovarian steroids during the rat oestrous cycle. Acta Endocrinol 85:449-455

34. Nequin LG, Alvarez J, Schwartz NB (1979) Measurement of serum steroid and gonadotropin levels and uterine and ovarian 
variables throughout the 4 day and 5 day estrous cycles in the rat. Biol Reprod 20:659-670

35. Haim S (2003) Serum levels of sex hormones and corticosterone throughout 4- and 5-day estrous cycles in Fischer 344 rats and their simulation in ovariectomized females. J Endocrinol Invest 26:1013-1022

36. Strange R, Westerlind KC, Ziemiecki A, Andres A-C (2007) Proliferation and apoptosis in mammary epithelium during the rat oestrus cycle. Acta Physiol 190:137-149. doi:10.1111/j.17481716.2007.01704.x
37. Guzman RC, Rajkumar L, Thordarson G, Nandi S (2005) Pregnancy levels of estrogen prevents mammary cancers. In: Li JJ, Li SA, Llombart-Bosch A (eds) Hormonal carcinogenesis IV. Springer, New York, pp 427-430

38. Sanyal MK (1978) Secretion of progesterone during gestation in the rat. J Endocrinol 79:179-190. doi:10.1677/joe.0.0790179

39. Macdonald GJ, Matt DW (1984) Adrenal and placental steroid secretion during pregnancy in the rat. Endocrinology 114:2068-2073. doi:10.1210/endo-114-6-2068 